\title{
Does afatinib plus bevacizumab combination therapy induce positive conversion of T790M in previously-negative patients?
}

\author{
Akito Hata ${ }^{1}$, Nobuyuki Katakami ${ }^{1}$, Reiko Kaji ${ }^{1}$, Toshihide Yokoyama ${ }^{2}$, Toshihiko \\ Kaneda ${ }^{2}$, Motohiro Tamiya ${ }^{3}$, Takako Inoue ${ }^{3}$, Hiromi Kimura ${ }^{4}$, Yukihiro Yano ${ }^{4}$, \\ Daisuke Tamura ${ }^{5}$, Satoshi Morita ${ }^{6}$ and Shunichi Negoro ${ }^{7}$ on behalf of HANSHIN \\ Oncology Group \\ ${ }^{1}$ Department of Medical Oncology, Kobe City Medical Center General Hospital, Kobe, Japan \\ ${ }^{2}$ Department of Respiratory Medicine, Kurashiki Central Hospital, Kurashiki, Japan \\ ${ }^{3}$ Department of Thoracic Oncology, Osaka International Cancer Institute, Osaka, Japan \\ ${ }^{4}$ Department of Thoracic Oncology, National Hospital Organization Toneyama National Hospital, Toyonaka, Japan \\ ${ }^{5}$ Department of Respiratory Medicine, Kobe University Graduate School of Medicine, Kobe, Japan \\ ${ }^{6}$ Department of Biomedical Statistics and Bioinformatics, Kyoto University Graduate School of Medicine, Kyoto, Japan \\ ${ }^{7}$ Department of Medical Oncology, Takarazuka City Hospital, Takarazuka, Japan \\ Correspondence to: Akito Hata, email: akitohata@hotmail.com
}

Keywords: afatinib; bevacizumab; T790M; rebiopsy; osimertinib

Received: August 12, $2018 \quad$ Accepted: September 13, $2018 \quad$ Published: October 05, 2018

Copyright: Hata et al. This is an open-access article distributed under the terms of the Creative Commons Attribution License 3.0 (CC BY 3.0), which permits unrestricted use, distribution, and reproduction in any medium, provided the original author and source are credited.

\section{ABSTRACT}

Third-generation epidermal growth factor receptor (EGFR)-tyrosine kinase inhibitors (TKIs) are markedly effective for T790M-positive patients. To confer their clinical benefit to more patients, a novel therapy to induce positive conversion in T790M-negative patients may be possible. We retrospectively reviewed medical records of patients who had received rebiopsy after completion of ABC-study: a prospective phase II study of Afatinib plus Bevacizumab Combination (ABC)-therapy after acquired resistance to EGFR-TKI. Between October 2014 and September 2016, 32 eligible patients were enrolled in ABC-study at our institutes. Eighteen patients were T790M-negative and 14 were T790M-positive before ABC-therapy. Rebiopsy was performed on $13 \mathrm{T790M}$-negative and $5 \mathrm{T790M}$-positive patients after progression of ABC-therapy. In $8(62 \%)$ of 13 T790M-negative patients, T790M status changed from negative to positive after ABC-therapy. Seven of these 8 patients underwent osimertinib therapy. The response rate and median time to treatment failure were $86 \%$ and 12.2 months, respectively. There were no adverse events $\geq$ grade 3 , nor any treatment-related deaths. On the other hand, T790M remained positive after ABCtherapy in all 5 previous T790M-positive patients. ABC-therapy could induce positive conversion of T790M even in previously-negative patients. We hypothesize that ABCtherapy could provoke "clonal selection", which purifies T790M-positive cancer cells in heterogeneous tumors. Further studies are warranted to confirm this phenomena.

\section{INTRODUCTION}

Epidermal growth factor receptor (EGFR)-tyrosine kinase inhibitor (TKI) is the standard of care for patients with EGFR-mutant advanced/metastatic non-small cell lung cancer (NSCLC). The progression-free survival (PFS) is approximately one year, and acquired resistance (AR) is mostly inevitable [1]. T790M point mutation in exon
20 is the major mechanism of AR, accounting for half of all AR mechanisms [2-4]. Third-generation (3G) EGFRTKIs are markedly effective and safe for T790M-positive patients $[5,6]$. Among 3G EGFR-TKIs, osimertinib is the only clinically available agent now. Unfortunately at present, osimertinib is only indicated in T790M-positive patients, thus T790M-negative patients cannot receive clinical benefit from osimertinib. To confer its clinical 
benefit to more patients, a novel therapy to induce positive conversion in T790M-negative patients may be possible.

We have reported results of our ABC-study evaluating the efficacy and safety of Afatinib plus Bevacizumab Combination (ABC) therapy after AR to EGFR-TKIs [7]. Interestingly, in some patients after completion of this study, T790M status had changed from negative to positive after ABC-therapy. According to this phenomena, we hypothesized that ABC-therapy could induce positive conversion of T790M in previouslynegative patients. The aim of this study was to investigate T790M status from rebiopsy results after ABC-therapy in patients who had been enrolled in $\mathrm{ABC}$-study.

\section{RESULTS}

\section{Patients}

We reviewed 32 eligible patients from our ABC-study. Patient characteristics are shown in Table 1. The median age was 66 (range, 48-86) years. Twenty-one (66\%) patients were female. The frequencies of sensitive EGFR mutation subtypes were 20 (63\%) Del-19, 11 (34\%) L858R, and 1 (3\%) L861Q. The response rate and disease control rate of afatinib plus bevacizumab were $18.8 \%$ and $90.7 \%$, respectively. Median PFS was 6.3 months [7]. Eighteen (56\%) patients underwent rebiopsy after ABC-therapy. Four patients received chemotherapies between progressive disease (PD) on ABC-therapy and rebiopsy, and remaining 14 patients were rebiopsied without chemotherapies after PD on ABC-therapy. Sensitive EGFR mutation status did not change before and after ABC-therapy in all studied cases.

\section{T790M status before and after afatinib plus bevacizumab}

Figure 1 shows T790M status before and after ABCtherapy. Eighteen patients were T790M-negative and 14 were T790M-positive before ABC-therapy. Rebiopsy was performed on 13 of 18 T790M-negative and 5 of 14 T790M-positive patients after progression on ABC-therapy. In $8(62 \%)$ of 13 T790M-negative patients, T790M status changed from negative to positive after ABC-therapy. On the other hand, T790M remained positive after ABCtherapy in all 5 previous T790M-positive patients.

\section{Osimertinib efficacy in cases converted from T790M-negative to -positive after afatinib plus bevacizumab}

Seven of 8 cases where T790M status changed from negative to positive after ABC-therapy underwent osimertinib therapy. The response rate and disease control rate were $86 \%$ and $100 \%$, respectively. The median time to treatment failure and overall survival were 12.2 (95\% CI, 3.0-undeterminable) months (Figure 2) and not reached, respectively. There were no adverse events $\geq$ grade 3 , nor any treatment-related deaths.

\section{Case presentation}

We herein describe a representative case of T790Mpositive conversion. The patient was 73 years-old male with EGFR-mutant (L858R) NSCLC. He received erlotinib as the first-line therapy for 1 year. After progression, rebiopsy was performed using bronchoscopy. T790M was negative, then ABC-therapy and carboplatin plus pemetrexed were administered as second- and third-line chemotherapies. After further progression, rebiopsy was carried out again to the same lesion and procedure. T790M was converted to positive, and osimertinib was initiated. Partial response was confirmed, and TTF was 12.2 months (Figure 3 ).

\section{DISCUSSION}

We have observed a positive conversion of T790M in some previously-negative patients with EGFR-mutant NSCLC. In $8(62 \%)$ of 13 T790M-negative patients,

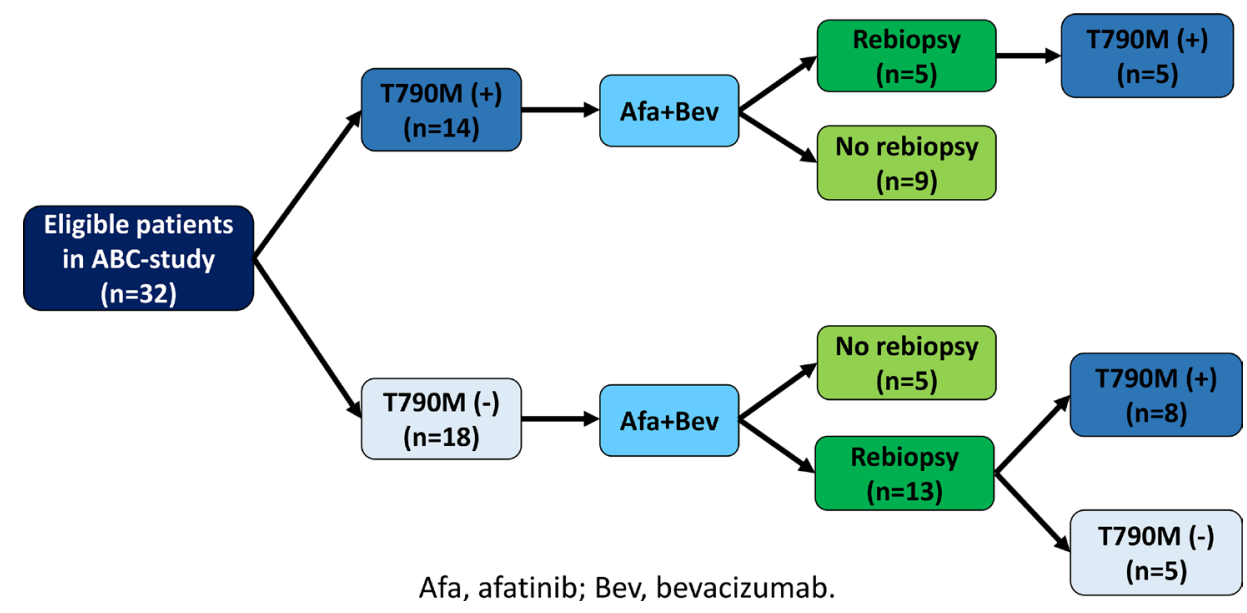

Figure 1: T790M status before and after afatinib plus bevacizumab. 
Table 1: Patient characterisics

\begin{tabular}{|c|c|c|c|c|c|c|c|}
\hline \# & $\begin{array}{l}\text { Age/ } \\
\text { Gender }\end{array}$ & $\begin{array}{c}\text { Primary } \\
\text { EGFR- } \\
\text { TKIs }\end{array}$ & $\begin{array}{l}\text { Sensitive } \\
\text { mutation }\end{array}$ & $\begin{array}{c}\text { T790M status before Afa }+ \text { Bev/ } \\
\text { Site/Method }\end{array}$ & $\begin{array}{l}\text { Response } \\
\text { /PFS (mo) }\end{array}$ & $\begin{array}{c}\text { T790M status after } \\
\text { Afa }+ \text { Bev/Site/Method }\end{array}$ & $\begin{array}{l}\text { Duration/Chemotherapy } \\
\text { between PD and rebiopsy }\end{array}$ \\
\hline 01 & $79 / F$ & $\mathrm{G}, \mathrm{E}$ & L861Q & T790M (-)/Lung/Clamp & $\mathrm{PR} / 13.1$ & 1 & / \\
\hline 02 & $56 / \mathrm{F}$ & $\mathrm{G}, \mathrm{E}$ & L858R & T790M (-)/Cardiac effusion/Clamp & $\mathrm{SD} / 5.1$ & $\begin{array}{l}\text { T790M (-)/Cardiac } \\
\text { effusion/Clamp }\end{array}$ & $0 \mathrm{mo} /$ None \\
\hline 03 & $55 / \mathrm{F}$ & $\mathrm{E}$ & Del-19 & T790M (-)/Lung/Clamp & $\mathrm{PD} / 1.4$ & $\begin{array}{l}\text { T790M (+)/Pleural } \\
\text { effusion/Clamp }\end{array}$ & $0 \mathrm{mo} /$ None \\
\hline 04 & $62 / \mathrm{F}$ & $\mathrm{G}, \mathrm{E}$ & L858R & T790M (-)/Lung/Clamp & $\mathrm{SD} / 3.4$ & T790M (-)/Lung/Clamp & $0.4 \mathrm{mo} /$ None \\
\hline 05 & $63 / \mathrm{M}$ & G & Del-19 & T790M (-)/Lung/Clamp & $\mathrm{PR} / 9.3$ & T790M (+)/Lung/Clamp & $0.4 \mathrm{mo} /$ None \\
\hline 06 & 73/M & E & L858R & T790M (-)/Lung/Clamp & $\mathrm{SD} / 8.7$ & T790M (+)/Lung/Clamp & $8.0 \mathrm{mo} / \mathrm{CBDCA}+\mathrm{PEM}$ \\
\hline 07 & $59 / \mathrm{M}$ & $\mathrm{G}, \mathrm{E}$ & Del-19 & T790M (-)/Pleural effusion/Clamp & $\mathrm{PD} / 1.0$ & 1 & 1 \\
\hline 08 & $73 / \mathrm{M}$ & $\mathrm{G}, \mathrm{E}$ & L858R & T790M (-)/Lung/Clamp & $\mathrm{SD} / 2.9$ & l & / \\
\hline 09 & $82 / \mathrm{M}$ & G & Del-19 & T790M (+)/Lung/Clamp & $\mathrm{SD} / 10.3$ & l & I \\
\hline 10 & $62 / \mathrm{M}$ & $\mathrm{E}$ & Del-19 & T790M (-)/Pleural effusion/Clamp & $\mathrm{PR} / 10.1$ & $\begin{array}{l}\text { T790M (+)/Pleural } \\
\text { effusion/MBP-QP }\end{array}$ & $0 \mathrm{mo} /$ None \\
\hline 11 & $79 / \mathrm{F}$ & G & Del-19 & T790M (+)/Pleural effusion/Clamp & $\mathrm{SD} / 2.5$ & $\begin{array}{l}\text { T790M (+)/Pleural } \\
\text { effusion/MBP-QP }\end{array}$ & $0 \mathrm{mo} /$ None \\
\hline 12 & $81 / \mathrm{F}$ & $\mathrm{G}, \mathrm{E}$ & Del-19 & T790M (+)/Lung/Clamp & $\mathrm{SD} / 9.1$ & $\begin{array}{c}\text { T790M (+)/Lung/MBP- } \\
\text { QP }\end{array}$ & $0.4 \mathrm{mo} /$ None \\
\hline 13 & $81 / \mathrm{F}$ & G & Del-19 & T790M (-)/Lung/Clamp & $\mathrm{SD} / 6.3$ & $\begin{array}{c}\text { T790M (+)/Lung/MBP- } \\
\text { QP }\end{array}$ & $\begin{array}{c}7.4 \mathrm{mo} / \mathrm{GEM}+\mathrm{Bev}, \text { nab- } \\
\text { PTX }\end{array}$ \\
\hline 14 & $63 / \mathrm{F}$ & G, Afa & Del-19 & T790M (+)/Lung/Clamp & $\mathrm{SD} / 2.6$ & 1 & 1 \\
\hline 15 & $65 / \mathrm{F}$ & G & Del-19 & T790M (+)/Pleural effusion/Clamp & $\mathrm{PD} / 1.1$ & $\begin{array}{l}\text { T790M (+)/Pleural } \\
\text { effusion/Clamp }\end{array}$ & $0 \mathrm{mo} /$ None \\
\hline 16 & $55 / \mathrm{M}$ & G & L858R & T790M (+)/Lung/Clamp & $\mathrm{SD} / 3.5$ & 1 & / \\
\hline 17 & $66 / \mathrm{M}$ & G & Del-19 & T790M (-)/Lung/Clamp & $\mathrm{SD} / 1.5$ & l & I \\
\hline 18 & $74 / \mathrm{F}$ & G & Del-19 & T790M (+)/Lymph node/Clamp & $\mathrm{SD} / 3.9$ & 1 & / \\
\hline 19 & $66 / \mathrm{M}$ & G & Del-19 & T790M (+)/Pleural effusion/Clamp & $\mathrm{SD} / 7.8$ & $\begin{array}{c}\text { T790M (+)/Pleural } \\
\text { effusion/Clamp }\end{array}$ & $0 \mathrm{mo} /$ None \\
\hline 20 & $80 / \mathrm{M}$ & $\mathrm{E}$ & Del-19 & T790M (+)/Pleural effusion/Clamp & $\mathrm{PR} / 5.8$ & 1 & 1 \\
\hline 21 & $64 / \mathrm{F}$ & G & Del-19 & T790M (-)/Lung/Cobas & $\mathrm{PR} / 5.1$ & T790M (+)/Lung/Clamp & $3.4 \mathrm{mo} / \mathrm{Afa}$ \\
\hline 22 & $48 / \mathrm{F}$ & G & Del-19 & T790M (-)/Lung/MBP-QP & $\mathrm{SD} / 2.9$ & T790M (-)/Lung/Cobas & $0.1 \mathrm{mo} /$ None \\
\hline 23 & $68 / \mathrm{F}$ & G, E, Afa & Del-19 & T790M (-)/Lung/MBP-QP & $\mathrm{SD} / 5.5$ & 1 & 1 \\
\hline 24 & $80 / \mathrm{M}$ & $\mathrm{E}$ & Del-19 & T790M (-)/Lung/MBP-QP & $\mathrm{SD} / 7.3$ & $\begin{array}{c}\text { T790M (-)/Lung/Clamp/ } \\
\text { MBP-QP }\end{array}$ & $0.3 \mathrm{mo} /$ None \\
\hline 25 & $86 / \mathrm{F}$ & $\mathrm{G}, \mathrm{E}$ & L858R & T790M (+)/Lung/Clamp & $\mathrm{SD} / 8.1$ & 1 & l \\
\hline 27 & $79 / \mathrm{F}$ & $\mathrm{G}$ & L858R & T790M (+)/Lung/Clamp & $\mathrm{SD} / 9.3$ & 1 & I \\
\hline 28 & $74 / \mathrm{F}$ & G & L858R & T790M (-)/Lung/MBP-QP & $\mathrm{SD} / 4.1$ & $\begin{array}{c}\text { T790M (+)/Lung/MBP- } \\
\text { QP }\end{array}$ & $0.2 \mathrm{mo} /$ None \\
\hline 29 & $46 / \mathrm{F}$ & G & Del-19 & T790M (+)/Lung/MBP-QP & $\mathrm{SD} / 9.5$ & $\begin{array}{c}\text { T790M (+)/Lung/MBP- } \\
\text { QP }\end{array}$ & $0.4 \mathrm{mo} /$ None \\
\hline 30 & $65 / \mathrm{F}$ & $\mathrm{E}$ & L858R & T790M (-)/Lung/MBP-QP & $\mathrm{SD} / 3.1+$ & 1 & / \\
\hline 31 & $67 / \mathrm{M}$ & Afa & Del-19 & T790M (+)/Pleural effusion/Clamp & $\mathrm{PR} / 9.9+$ & 1 & / \\
\hline 32 & $51 / \mathrm{F}$ & G, E, Afa & Del-19 & T790M (-)/Lung/MBP-QP & $\mathrm{SD} / 7.8$ & $\begin{array}{c}\text { T790M (+)/Lung/MBP- } \\
\text { QP }\end{array}$ & $0.4 \mathrm{mo} /$ None \\
\hline 33 & $62 / \mathrm{F}$ & E, Afa & Del-19 & T790M (-)/Lung/Cobas & $\mathrm{SD} / 2.8$ & $\begin{array}{l}\text { T790M (-)/Pleural } \\
\text { effusion/Clamp }\end{array}$ & $3.3 \mathrm{mo} / 4$ regimens ${ }^{\#}$ \\
\hline
\end{tabular}

Abbreviations: M, male; F, female; EGFR-TKI, epidermal growth factor receptor-tyrosine kinase inhibitor; G, gefitinib; E, erlotinib; Afa, afatinib; PR, partial response; SD, stable disease; PD, progressive disease; PFS, progression-free survival; mo, months; CBDCA, carboplatin; PEM, pemetrexed; GEM, gemcitabine; Bev, bevacizumab; nab-PTX, nanoparticle albumin bound-paclitaxel; Clamp, peptide nucleic acid-locked nucleic acid PCR clamp method; and mutation-biased PCR quenching probe method.

Case 26 and 34 were ineligible.

\#, docetaxel plus ramucirumab, nab-PTX, Gefitinib+GEM, S-1+Bev. 
T790M status changed from negative to positive after ABC-therapy. A few studies found $30-40 \%$ of T790Mpositive conversion in previously-negative patients by sequential rebiopsy results $[8,9]$. Some studies have also shown T790M conversion from negative to positive [10, 11]. Our $62 \%$ of T790M-positive conversion is relatively higher than these previous reports, suggesting causes other than false negatives from previous T790M-negative.

We assumed three mechanisms which caused this phenomenon. First is our hypothesis: clonal selection induced by ABC-therapy. Afatinib plus bevacizumab exerts a strong synergistic effect against cancer cells after acquired resistance to EGFR-TKIs [12]. Afatinib also has high sensitivity to cancer cells harboring uncommon/ minor EGFR mutations and HER2-4 [13, 14]. Erlotinib plus bevacizumab was reported to be potentially effective against MET-amplified cancer cells after AR in preclinical study [15]. This data might imply similar sensitivity of afatinib plus bevacizumab to MET-amplified cancer cells. ABC-therapy could eliminate heterogenous clones other than T790M-positive clones, and could purify T790Mpositive clones in heterogenous tumors (Figure 4). Second, spatiotemporal heterogeneity of T790M could affect this phenomenon. We previously reported T790M spatiotemporal heterogeneity suggested by results of multiple rebiopsy [11]. In patient \#3, rebiopsy was done to lung before $\mathrm{ABC}$-therapy, and to pleural effusion after ABC-therapy. This case implies spatial T790M heterogeneity between lung and pleural effusion. Some cases might have exhibited a temporal T790M heterogeneity. Before ABC-therapy, selective pressure from prior EGFR-TKIs might have been insufficient to change T790M-negative results. After ABC-therapy, selective pressure might have increased enough and might have induced T790M-positive results [11]. This T790M temporal heterogeneity is due to TKI selective pressure, which may suggest similar phenomenon to our hypothesis of clonal selection. Third, is a possible differential result by different procedural manner. In patient $\# 21$, rebiopsy was performed using cobas before ABC-therapy, and using PNA-LNA PCR clamp after ABC-therapy. Sensitivity of cobas and PNA-LNA PCR clamp are considered as 5\% and $1 \%$, respectively $[5,16]$. That of MPB-QP is regarded as $1 \%$ [17]. In some cases with T790M-positive conversion, PNA-LNA PCR clamp was used before ABC-therapy, and MPB-QP after ABC-therapy. Although sensitivities between them are similar, differential procedual manners might have affected T790M-positivity.

In seven cases where T790M status changed from negative to positive after $\mathrm{ABC}$-therapy, the response rate and disease control rate of osimertinib were $86 \%$ and $100 \%$, respectively. The median TTF was 12.2 months. These results were similar or slightly better than historical results of osimertinib for pretreated T790M-positive NSCLC $[5,6]$. Our hypothesized clonal selection might have affected these favorable results. T790M-purified cancer after ABC-therapy could have responded well to osimertinib. Notably, Sequist et al. have reported longer TTF of osimertinib after afatinib than after gefitinib [18]. They also hypothesize clonal selection by afatinib affected longer TTF. Results of their and our studies could complement each other and support our hypothesis of clonal selection.

Unfortunately, our study is too small to identify significant predictive factors for T790M-positive conversion. However, T790M-positive conversion seemed to be more evident in those with better response to ABCtherapy. Six (75\%) of 8 cases with T790M-positive conversion obtaind $\mathrm{PR} / \mathrm{SD} \geq 6$ months. T790M-positive conversion might be associated with response to $\mathrm{ABC}$ therapy, suggesting a possible deeper clonal selection.

Our study was retrospective and small sample size, including several limitations. After ABC-therapy, not

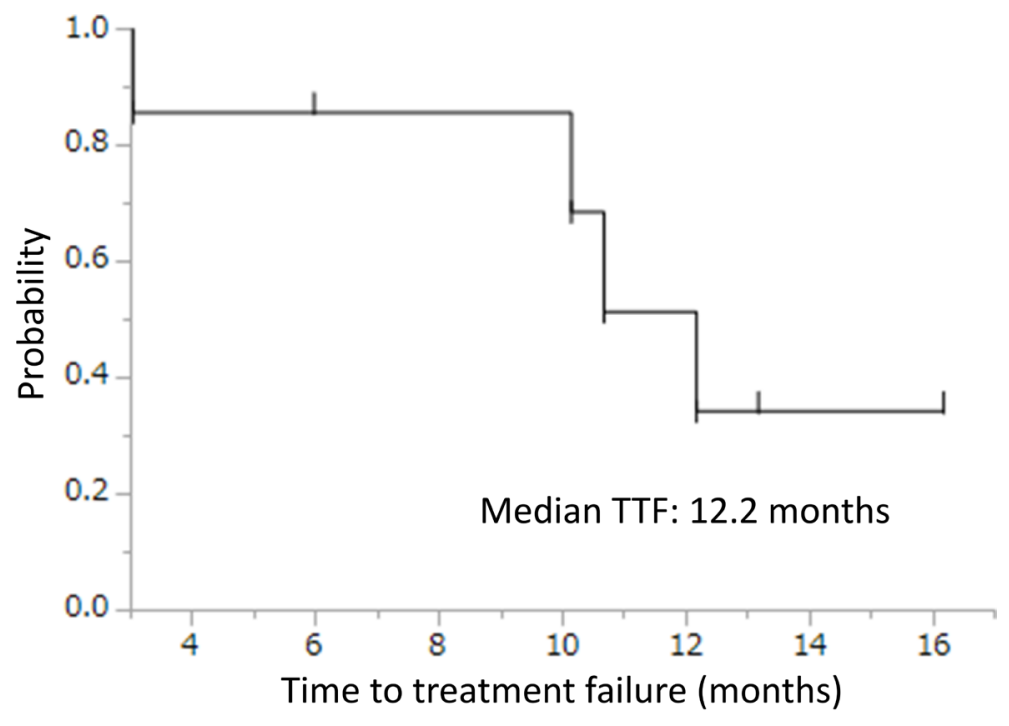

TTF, time to treatment failure.

Figure 2: Time to treatment failure of osimertinib. 
all patients underwent rebiopsy. Patients who were able to receive rebiopsy had targetable lesions and relatively higher tumor burdens than those without targetable lesions. This could be a selection bias. Tumor response and PFS of osimertinib were evaluated using the RECIST, but durations of CT scans depended on doctors in charge. These variable durations also could be a bias of our study. This could largely affect PFS, thus we adopt TTF as an evaluation of therapeutic duration. We hypothesized clonal selection by ABC-therapy, but resistant mechanisms in T790M-negative samples were not investigated, and tumor heterogeneity was not definitively confirmed, but just speculation. After approval

\section{(1)Erlotinib: \\ Partial response for 1 year \\ (2)Afatinib+bevacizumab: \\ Stable disease for 10 months \\ (3) Carboplatin+pemetrexed Stable disease for 4 months}

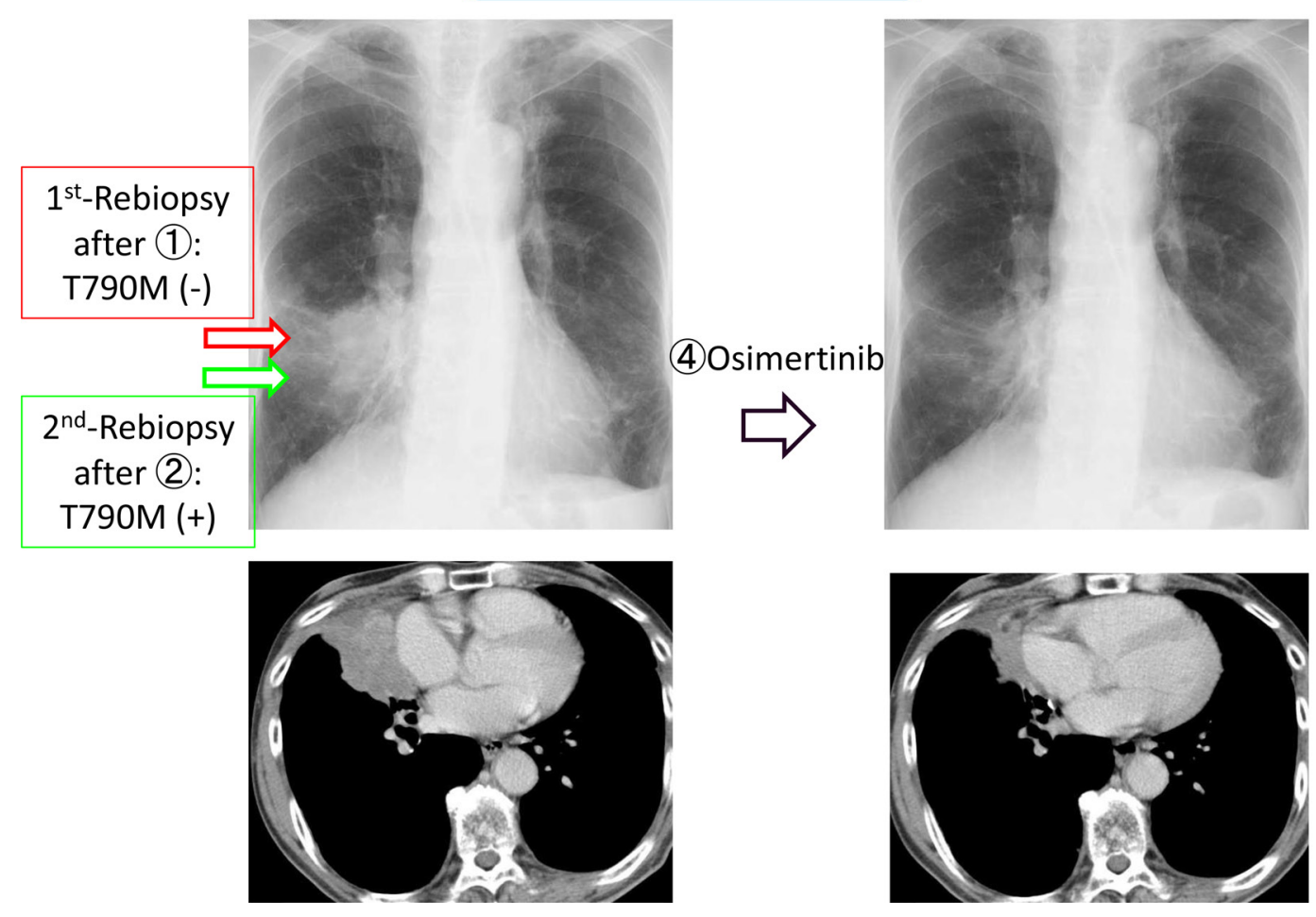

Figure 3: Presentation of case \#6.

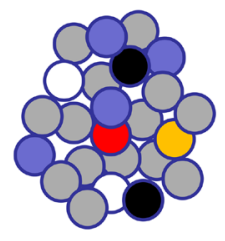

Heterogenous tumor T790M (-) by PCR
Afa+Bev

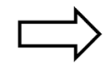

\section{Responded tumor}

\section{Afa+Bev}
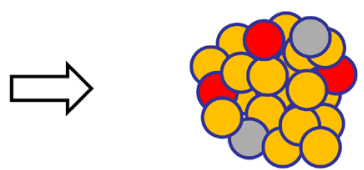

T790M purified progressive tumor T790M (+) by PCR

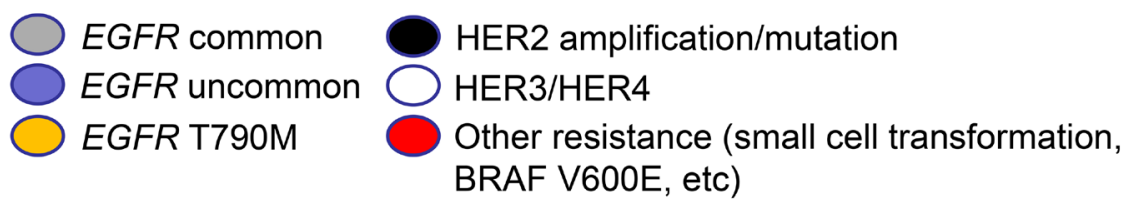

Afa, afatinib; Bev, bevacizumab; EGFR, epidermal growth factor receptor.

Figure 4: Hypothesis of "clonal selection". 
of next generation sequencers in the near future, compound mutations could be examined before and after ABC-therapy, which could confirm the hypothesis of clonal selection.

Afatinib can inhibit both uncommon EGFR mutations and pan-HER signals. If clonal selection is induced by only afatinib monotherapy, the T790M incidence after afatinib would be higher than that after gefitinib or erlotinib. However, Wu SG et al. showed that the T790M incidence after afatinib was $47.6 \%$, similar to gefitinib or erlotinib [19]. Sensitivity to afatinib monotherapy might be insufficient, and additional bevacizumab to afatinib could be necessary to induce clonal selection. However, this basic mechanism is unclear. Actual advantage of and reason to convert T790M by additional bevacizumab are unknown and warrant further investigations.

We also should consider "de novo" T790M mutation as another mechanism of T790M-positive conversion. Hata AN et al. showed acquired T790M mutation can occur via either selection of pre-existing T790M-positive clones or genetic evolution of initially T790M-negative drug-tolerant cells [20]. De novo T790M mutation could provoke positive-conversion of an initial T790M-negative tumor.

In conclusion, $\mathrm{ABC}$-therapy could induce positive conversion of $\mathrm{T} 790 \mathrm{M}$ even in previously-negative patients. We hypothesize that $\mathrm{ABC}$-therapy could provoke "clonal selection", which purifies T790M-positive cancer cells in heterogeneous tumors. This ABC-therapy could confer clinical benefit of osimertinib to more patients without T790M by T790M positive conversion. Further studies are warranted to confirm this phenomena.

\section{MATERIALS AND METHODS}

\section{Study design}

This study was a retrospective study involving patients after completion of ABC-study: Afatinib plus Bevacizumab Combination after AR to EGFR-TKIs in EGFR-mutant non-small cell lung cancer, a prospective multicenter, singlearm, open-label phase II trial conducted by the HANSHIN Oncology Group to evaluate the clinical efficacy and safety of ABC-therapy after AR in EGFR-mutant NSCLC. ABC-study demanded examination of T790M status before enrollment. Patients of unknown T790M status were ineligible. After primary EGFR-TKI therapy before $\mathrm{ABC}$-therapy, all enrolled patients to $\mathrm{ABC}$-study received rebiopsy. The aims of this study were: first, to examine T790M status before and after ABC-therapy; and second, to evaluate the efficacy of osimertinib in cases converted from T790M-negative to -positive after ABC-therapy. The study was conducted in accordance with the Declaration of Helsinki with the approval of institutional review board.

T790M status was examined using relatively sensitive PCR methods such as the peptide nucleic acid (PNA)locked nucleic acid (LNA) PCR clamp, the mutation-biased PCR quenching probe method or the cobas $[5,16,17]$.
Osimertinib was prescribed in our clinical practice. The efficacy and safety were evaluated according to the Response Evaluation Criteria in Solid Tumors (RECIST) version 1.1 and the National Cancer Institute Common Terminology Criteria for Adverse Events version 4.0, respectively.

Time to treatment failure (TTF) and overall survival (OS) curves and 95\% confidence intervals (CIs) were estimated by the Kaplan-Meier method. The statistical analyses were performed using JMP 12 (SAS Institute, Inc., Cary, NC, USA).

\section{Author contributions}

Conceptualization, AH and NK; Methodology, AH and NK; Software, AH; Validation, AH, NK, and SM; Formal analysis, $\mathrm{AH}, \mathrm{NK}$, and $\mathrm{SM}$; Investigation, $\mathrm{AH}$ and NK; Resources, All authors; Data curation, All authors; Writing-original draft, $\mathrm{AH}$ and $\mathrm{NK}$; Writing-review and editing, All authors; Visualization, $\mathrm{AH}, \mathrm{NK}$, and $\mathrm{SN}$; Supervision, AH, NK and SN; and Project administration, $\mathrm{AH}, \mathrm{NK}$, and $\mathrm{SN}$.

\section{ACKNOWLEDGMENTS}

This study had no financial support. The authors appreciate the participating patients and member of the HANSHIN Oncology Group. We thank Ms. Edagawa and Ms. Mizushima for data management and Mr. David Martin for English writing support.

\section{CONFLICTS OF INTEREST}

Akito Hata received lecture fees from Chugai, Astra Zeneca, Boehringer Ingelheim, and Eli Lilly. Dr. Katakami received grants from Astra Zeneca, Eisai, Ono, Kyowa Kirin, Shionogi, Daiichi-Sankyo, Taiho, Chugai, Eli Lilly, Boehringer Ingelheim, and Merck Serono, and payment for lectures from Dainippon Sumitomo, Chugai, Boehringer Ingelheim, Astra Zeneca, Eli Lilly, Taiho, Janssen, Novartis, Pfizer, Ono, and Daiichi-Sankyo. The other authors declare no conflict of interest.

\section{GRANT SUPPORT}

None.

\section{REFERENCES}

1. Lee $\mathrm{CK}, \mathrm{Wu} \mathrm{YL}$, Ding PN, Lord SJ, Inoue A, Zhou C, Mitsudomi T, Rosell R, Pavlakis N, Links M, Gebski V, Gralla RJ, Yang JC. Impact of Specific Epidermal Growth Factor Receptor (EGFR) Mutations and Clinical Characteristics on Outcomes After Treatment With EGFR Tyrosine Kinase Inhibitors Versus Chemotherapy in EGFR-Mutant Lung Cancer: A Meta-Analysis. J Clin Oncol. 2016; 33:1958-1965. 
2. Pao W, Miller VA, Politi KA, Riely GJ, Somwar R, Zakowski MF, Kris MG, Varmus H. Acquired resistance of lung adenocarcinomas to gefitinib or erlotinib is associated with a second mutation in the EGFR kinase domain. PLoS Med. 2005; 2:e73.

3. Kobayashi S, Boggon TJ, Dayaram T, Jänne PA, Kocher O, Meyerson M, Johnson BE, Eck MJ, Tenen DG, Halmos B. EGFR mutation and resistance of non-small-cell lung cancer to gefitinib. N Engl J Med. 2005; 352:786-792.

4. Yu HA, Arcila ME, Rekhtman N, Sima CS, Zakowski MF, Pao W, Kris MG, Miller VA, Ladanyi M, Riely GJ. Analysis of tumor specimens at the time of acquired resistance to EGFR-TKI therapy in 155 patients with EGFR-mutant lung cancers. Clin Cancer Res. 2013; 19:2240-2247.

5. Jänne PA, Yang JC, Kim DW, Planchard D, Ohe Y, Ramalingam SS, Ahn MJ, Kim SW, Su WC, Horn L, Haggstrom D, Felip E, Kim JH, et al. AZD9291 in EGFR inhibitor-resistant non-small-cell lung cancer. N Engl J Med. 2015; 372:1689-1699.

6. Mok TS, Wu YL, Ahn ML, Garassino MC, Kim HR, Ramalingam SS, Shepherd FA, He Y, Akamatsu H, Theelen WS, Lee CK, Sebastian M, Templeton A, et al; AURA3 Investigators. Osimertinib or Platinum-Pemetrexed in EGFR T790M-Positive Lung Cancer. N Engl J Med. 2017; 376:629-640.

7. Hata A, Katakami N, Kaji R, Yokoyama T, Kaneda T, Tamiya M, Inoue T, Kimura H, Yano Y, Tamura D, Morita S, Negoro S; HANSHIN Oncology Group. Afatinib Plus Bevacizumab Combination after Acquired Resistance to EGFR-TKIs in EGFR-Mutant Non-Small Cell Lung Cancer: Multicenter Single-Arm Phase II Trial (ABCStudy). Cancer. 2018 Sep 7. [Epub ahead of print].

8. Kuiper JL, Heideman DA, Thunnissen E, Paul MA, van Wijk AW, Postmus PE, Smit EF. Incidence of T790M mutation in (sequential) rebiopsies in EGFR-mutated NSCLC-patients. Lung Cancer. 2014; 85:19-24.

9. Ichihara E, Hotta K, Kubo T, Higashionna T, Ninomiya K, Ohashi K, Tabata M, Maeda Y, Kiura K. Clinical significance of repeat rebiopsy in detecting the EGFR T790M secondary mutation in patients with non-small cell lung cancer. Oncotarget. 2018; 9:29525-29531. https://doi.org/10.18632/oncotarget.25705.

10. Sequist LV, Waltman BA, Dias-Santagata D, Digumarthy S, Turke AB, Fidias P, Bergethon K, Shaw AT, Gettinger S, Cosper AK, Akhavanfard S, Heist RS, Temel J, et al. Genotypic and histological evolution of lung cancers acquiring resistance to EGFR inhibitors. Sci Transl Med. 2011; 3:75ra26.

11. Hata A, Katakami N, Yoshioka H, Kaji R, Masago K, Fujita S, Imai Y, Nishiyama A, Ishida T, Nishimura Y, Yatabe Y. Spatiotemporal T790M Heterogeneity in Individual Patients with EGFR-Mutant Non-Small-Cell Lung Cancer after Acquired Resistance to EGFR-TKI. J Thorac Oncol. 2015; 10:1553-1559.
12. Ninomiya T, Takigawa N, Ichihara E, Ochi N, Murakami T, Honda Y, Kubo T, Minami D, Kudo K, Tanimoto M, Kiura $\mathrm{K}$. Afatinib prolongs survival compared with gefitinib in an epidermal growth factor receptor-driven lung cancer model. Mol Cancer Ther. 2013; 12:589-597.

13. Kobayashi Y, Mitsudomi T. Not all epidermal growth factor receptor mutations in lung cancer are created equal: Perspectives for individualized treatment strategy. Cancer Sci. 2016; 107:1179-1186.

14. Li D, Ambrogio L, Shimamura T, Kubo S, Takahashi M, Chirieac LR, Padera RF, Shapiro GI, Baum A, Himmelsbach F, Rettig WJ, Meyerson M, Solca F, et al. BIBW2992, an irreversible EGFR/HER2 inhibitor highly effective in preclinical lung cancer models. Oncogene. 2008; 27:4702-4711.

15. Furugaki K, Fukumura J, Iwai T, Yorozu K, Kurasawa M, Yanagisawa M, Moriya Y, Yamamoto K, Suda K, Mizuuchi H, Mitsudomi T, Harada N. Impact of bevacizumab in combination with erlotinib on EGFR-mutated non-small cell lung cancer xenograft models with T790M mutation or MET amplification. Int J Cancer. 2016; 138:1024-1032.

16. Nagai Y, Miyazawa H, Huqun, Tanaka T, Udagawa K, Kato M, Fukuyama S, Yokote A, Kobayashi K, Kanazawa M, Hagiwara K. Genetic heterogeneity of the epidermal growth factor receptor in non-small cell lung cancer cell lines revealed by a rapid and sensitive detection system, the peptide nucleic acid-locked nucleic acid PCR clamp. Cancer Res. 2005; 65:7276-7282.

17. Nakamura T, Sueoka-Aragane N, Iwanaga K, Iwanaga K, Sato A, Komiya K, Abe T, Ureshino N, Hayashi S, Hosomi T, Hirai M, Sueoka E, Kimura S. A noninvasive system for monitoring resistance to epidermal growth factor receptor tyrosine kinase inhibitors with plasma DNA. J Thorac Oncol. 2011; 6:1639-1648.

18. Sequist LV, Wu YL, Schuler M, Kato T, Yang JC, Tanaka H, Hida T, Lu S, Park K, Laurie S, Bennouna J, Sibilot DM, Märten A, et al. Subsequent therapies post-afatinib among patients with EGFRmutation-positive NSCLC in LUXLung (LL) 3, 6 and 7. Journal of Thoracic Oncology. 2017; 12(Supplement 1):S1572.

19. Wu SG, Liu YN, Tsai MF, Chang YL, Yu CJ, Yang PC, Yang JC, Wen YF, Shih JY. The mechanism of acquired resistance to irreversible EGFR tyrosine kinase inhibitorafatinib in lung adenocarcinoma patients. Oncotarget. 2016; 7:12404-12413. https://doi.org/10.18632/oncotarget.7189.

20. Hata AN, Niederst MJ, Archibald HL, Gomez-Caraballo M, Siddiqui FM, Mulvey HE, Maruvka YE, Ji F, Bhang HE, Krishnamurthy Radhakrishna V, Siravegna G, Hu H, Raoof $\mathrm{S}$, et al. Tumor cells can follow distinct evolutionary paths to become resistant to epidermal growth factor receptor inhibition. Nat Med. 2016; 22:262-269. 